\title{
Solid Dispersions of Gefitinib Prepared by Spray Drying with Improved Mucoadhesive and Drug Dissolution Properties
}

\author{
Wesam W. Mustafa, ${ }^{1,2,4}$ John Fletcher, ${ }^{1}$ Mouhamad Khoder, ${ }^{1}$ and Raid G. Alany ${ }^{1,3}$
}

Received 16 June 2021; accepted 29 November 2021; published online 4 January 2022

\begin{abstract}
Gefitinib is a tyrosine kinase inhibitor that is intended for oral administration yet suffers poor bioavailability along with undesirable side effects. To enhance its solubility and allow colon targeting, gefitinib (ZD) and blends of different ratios of polymers (ternary dispersion) were prepared in organic solution, and solid dispersions were generated employing the spray drying (SD) technique. The methylmethacrylate polymer Eudragit $S$ 100 was incorporated for colon targeting; polyvinylpyrrolidone (PVP) and hydroxypropyl methyl cellulose (HPMC) were utilised to improve the solubility of ZD. SEM, DSC, XRPD, FT-IR, dissolution and cytotoxicity studies were undertaken to characterise and evaluate the developed formulations. SEM images revealed that the rod-shaped crystals of ZD were transformed into collapsed spheres with smaller particle size in the spray-dried particles. DSC, FTIR and XRPD studies showed that ZD loaded in the spray-dried dispersions was amorphous. ZD dissolution and release studies revealed that while a significant $(P<0.05)$ increase in the ZD dissolution and release was observed from HPMC-based solid dispersion at $\mathrm{pH} 7.2$ (up to $95 \%$ in $15 \mathrm{~h}$ ), practically no drug was released at $\mathrm{pH} 1.2$ and $\mathrm{pH} 6.5$. Furthermore, the HPMC-based solid dispersions displayed enhanced mucoadhesive properties compared with PVP-based ones. Interestingly, cell viability studies using the neutral red assay showed that PVP and HPMC-based solid dispersions had no additional inhibitory effect on Caco-2 cell line compared to the pure drug.
\end{abstract}

KEY WORDS: gefitinib; Eudragit S 100; PVP; HPMC; solid dispersion; colon-targeting.

\section{INTRODUCTION}

Gefitinib (ZD) is a specific epidermal growth factor receptor (EGFR) tyrosine kinase inhibitor that inhibits signal pathways involved in the growth of solid tumour and metastasis. ZD was approved as a single agent for treatment of non-small cell lung cancer. The mechanism of action of ZD has been linked to its targeted inhibition to EGFR tyrosine kinase by binding to the adenosine triphosphate (ATP) (1). Hence, the role of the EGFR tyrosine kinase in stimulating the anti-apoptotic Ras signal transduction cascade is inhibited, and therefore, the tumour cell activities are also

\footnotetext{
${ }^{1}$ Drug Discovery, Delivery and Patient Care Theme, Department of Pharmacy, Kingston University London, Kingston upon Thames, KT1 2EE, UK

${ }^{2}$ Department of Pharmacy, Al-Mustafa University College, Baghdad, Iraq.

${ }^{3}$ School of Pharmacy, The University of Auckland, Auckland, New Zealand.

${ }^{4}$ To whom correspondence should be addressed. (e-mail: w.mustafa@kingston.ac.uk)
}

Abbreviations: Eud, Eudragit S100; HPMC, Hydroxypropyl methyl cellulose; $P V P$, Polyvinylpyrrolidone; $S D$, Spray dried; $Z D$, Gefitinib. inhibited (2). For colorectal cancer treatment, studies on ZD have taken multiple paths. In patients with colon cancer, there is a theoretical rationale to the use of ZD. As in colorectal tumours where the EGFR is over-expressed, this over-expression is related with a worse prognosis (3).

Site-specific drug delivery has gained considerable interest over systemic therapy as it allows reducing drug dose and dose frequency by directing the drug at the disease spot and preventing metabolism of the drug, hence enhancing efficacy and reducing side effects $(4,5)$. Targeting the drug release to the colon for the local treatment of colonic disorders and cancers has appealed to researchers and clinicians $(6,7)$. Colon-targeted delivery has gained much popularity for treating local diseases of the colon such as ulcerative colitis and colon cancer. These targeted dosage forms can provide high local drug concentration with minimal systemic side effects. Colon cancer is one of the most commonly diagnosed cancers that causes cancer-related death worldwide $(8,9)$.

One of the most widely used approaches for developing successful colon-targeted drug delivery is coating drug particles with $\mathrm{pH}$-sensitive polymers (such as Eudragit S100). Such a strategy would prevent premature and undesirable rupture of the polymeric membrane in upper parts of 
the gastrointestinal tract such as the stomach and intestine. Spray drying is a successful and widely used technique to prepare coated particulate drug delivery system for different purposes including colon-targeted drug delivery (10).

$\mathrm{ZD}$ is a weak base with pKa values of 5.4 and 7.2; its insoluble in water and can be considered as a Class II drug based on the Biopharmaceutical Classification Scheme. Accordingly, ZD has low solubility and high permeability (11-14). ZD is formulated as a tablet for oral delivery to treat lung cancer (15). The fact that ZD is a poorly water-soluble drug that is intended to treat colorectal cancer via oral delivery warrants the need for an oral formulation that is able to simultaneously achieve a dual purpose and enhance its solubility and deliver it specifically to the colon. Although colon cancer at stage 0 and stage 1 can be managed by surgical intervention, the oral administration of anticancer agent (i.e. ZD) is preferred by both health care professional and patient. Moreover, a successful colonic delivery of anticancer agent helps localise the drug at the target site and provide the colon area with a more soluble form of the drug in a controlled release profile.

It has been previously reported that the lack of free fluid in the transverse and descending colon contributes to the incomplete release and dissolution of the drugs leading to therapeutic ineffectiveness (16). Therefore, releasing the drug at the ileo-colonic segment is preferred where more fluids, hence the rationale for using a formulation with mucoadhesive characteristics. Furthermore, enhancing the drug dissolution rate is essential to allow complete drug release. The use of a solid dispersion, in which the drug is dispersed within one or more inert water-soluble carriers, is an established approach to overcome a poor dissolution profile (17). For ideal ileo-colonic targeting, the dosage form should effectively prevent drug release in the upper gastro-intestinal tract (GIT) only releasing the drug as it reaches the colon (18).

In this study, two hydrophilic polymers PVP and HPMC were selected as carriers for spray-dried solid dispersions to enhance the solubility and dissolution profile of ZD (19, 20). Furthermore, HPMC as a mucoadhesive polymer could potentially prolong contact time with the drug absorption surface to enhance tissue permeability of $\mathrm{ZD}$ and, thus, improve absorption and potentially increase efficacy and reduce adverse effects of the drug (21). Eudragit S 100, a pH-dependent polymer was selected as a secondary polymer in ternary dispersion to target the drug to the intended site (i.e. ileo-colonic site) (22). Eudragit S 100 is widely used in modified-release formulations (23).

Scanning electron microscopy, differential scanning calorimetry and X-ray diffractometry techniques were used to characterise the formulated solid dispersion and dissolution studies were performed over a range of biorelevant $\mathrm{pH}$ values to investigate the drug dissolution and release profiles. The in vitro model developed by Needleman et al.(24) was used to evaluate the mucoadhesive properties of selected formulations. Finally, neutral red assay was performed to assess the cytotoxicity of the pure ZD and ZD formulated in HPMCbases solid dispersions on Caco-2 cell line.

\section{MATERIALS AND METHODS}

\section{Materials}

Gefitinib (ZD) (ZD1839) was purchased from Med Chem Express Co., Ltd. (Shanghai, China). The Caco-2 cell line, trifluoroacetic acid (TFA), foetal bovine serum (FBS), thiazolyl blue tetrazolium bromide, l-glutamine-penicillinstreptomycin solution, dimethyl sulfoxide (DMSO), Eagle's minimum essential medium (EMEM), trypsin-EDTA solution, trypan blue solution $(0.4 \%)$, neutral red and actinomycin D were all purchased from Sigma-Aldrich (Dorset, UK). Acetone, sodium hydroxide and absolute ethanol were obtained from VWR International (Leicestershire, UK). Hydrochloric acid, Dulbecco's phosphate-buffered saline (PBS), sodium chloride, Dulbecco's modified Eagle's medium (DMEM), potassium dihydrogen orthophosphate, acetic acid glacial and Nunclon 96-well microplates were purchased from Fisher Scientific UK Ltd. (Loughborough, UK). Eudragit S 100 was provided by Evonik Röhm Gmbh (Essen, Germany). Kollidon K 30 (PVP) was kindly donated by BASF SE (Ludwigshafen, Germany). HPMC 603 (HPMC) was kindly given by Shin-Etsu Chemical Co., Ltd. (Tokyo, Japan).

\section{Solid Dispersions Preparation}

Specific amount of ZD ( $1 \mathrm{~g})$ was dissolved in a mixture of acetone $(60 \mathrm{~mL})$ and ethanol $(40 \mathrm{~mL})$. Then, PVP and/or HPMC (see Table 1 for quantities and compositions) were added gradually with stirring for $20 \mathrm{~min}$ to dissolve. Distilled water $(20 \mathrm{~mL})$ was then added to the PVP solution stirred solution. For HPMC mixtures of different polymer content, $10 \mathrm{~mL}$ of hot water and then $10 \mathrm{~mL}$ of cold water were added to the specified amount of HPMC. Finally, specified amounts of Eudragit S100 (see Table 1 for quantities and compositions) to yield a 1:9 final drug (10 g batch): polymer mass $(\mathrm{w} / \mathrm{w})$ ratios.

The resulting mixture was stirred for a further $30 \mathrm{~min}$ before being spray-dried using mini spray dryer (Büchi B-290, Büchi Labortechnik AG, Switzerland). The spray drier was set off with the inlet temperature of $90^{\circ} \mathrm{C}$, feeding rate of 3 $\mathrm{mL} / \mathrm{min}$, atomising air pressure of $3000 \mathrm{psi}$ and rate of nitrogen gas of $600 \mathrm{~L} / \mathrm{h}$ with $100 \%$ aspiration. The percentage yield was between 84 and $86 \%$.

\section{Scanning Electron Microscopy}

A Zeiss EVO 50 Scanning Electron Microscope (SEM) (Oberkochen, Germany) was employed to investigate the morphology and particle size of ZD, PVP, HPMC, Eudragit S100 and the solid dispersions. An SEM sample was prepared by coating the particles with a thin layer of gold to ensure adequate conductivity to the sample's surface using a Polaron SC500 sputter coater (Polaron Equipment, Watford, UK) under argon. Powdered samples were mounted on adhesive carbon tape fixed on metal stubs and examined under low vacuum mode at an acceleration voltage of $20 \mathrm{keV}$.

\section{X-ray Diffractometry (XRD)}

A BrukerAXS D8 X-ray diffractometer (Karlsruhe, Germany) was used to obtain the diffraction patterns of the raw materials (ZD, PVP, HPMC) and solid dispersions. The voltage and current used were $20 \mathrm{kV}$ and $5 \mathrm{~mA}$, respectively. The scan region was from $11^{\circ}$ to $30^{\circ} 2 \theta$ with a step size of $0.2^{\circ}$ $2 \theta$ and a time per step $0.18 \mathrm{~s}$ at room temperature. The 
Table 1. Drug to Polymer Ratios of Formulations Investigated in This Study ${ }^{*},{ }^{* * *}$

\begin{tabular}{llllll}
\hline S. No & Formulation code & ZD $(\mathrm{g})$ & \multicolumn{2}{l}{ Polymer content $(\mathrm{g})$} & Eudragit S 100 (g) \\
& & & PVP & HPMC \\
\hline 1 & SDZDPS & 1.0 & 7.2 & - & 1.8 \\
2 & SDZDHS & 1.0 & - & 7.2 & 1.8 \\
3 & SDZDHS-M & 1.0 & - & 7.1 & 1.9 \\
4 & SDZDHS-Z & 1.0 & - & 7.0 & 2.0 \\
\hline
\end{tabular}

"The formulated solid dispersions codes were constructed in a manner to better elucidate their constituents. For example, in 'SDZDPS' or 'SDZDHS', SD represents solid dispersions, while (ZDPS or ZDHS) represents solid dispersion constituents of gefitinib (ZD), PVP, Eudragit S 100 for ZDPS; and gefitinib (ZD), HPMC, Eudragit S 100 for ZDHS

${ }^{* *} \mathrm{M}$ or $\mathrm{Z}$ indicates the polymer content for HPMC and Eudragit S 100 in the dispersions (as shown in the above table)

resultant diffraction patterns were analysed using DIFFRAC plus XRD commander software.

\section{Differential Scanning Calorimetry (DSC)}

ZD, PVP, HPMC and the solid dispersions were thermally evaluated using a DSC 822e apparatus (MettlerToledo Ltd., Leicester, UK). Accurately weighed sample (3$10 \mathrm{mg}$ ) was loaded into a sealed pinhole aluminium crucible pan and placed on the top of the sample holder, under nitrogen flow of $10 \mathrm{~mL} \mathrm{~min}{ }^{-1}$. All samples were heated from room temperature up to a maximum of $230^{\circ} \mathrm{C}$ at $20^{\circ} \mathrm{C} / \mathrm{min}$, and results were analysed using STAReSW 10.00 software.

\section{Fourier-Transform Infrared (FT-IR) Spectroscopy}

Thermo Fisher Scientific FT-IR spectrometer (Nicolet iS5, iD5 advanced attenuated total reflectance (ATR), USA) was employed in this study. A collection of the spectrum occurred in the range of 4000 to $600 \mathrm{~cm}^{-1}$. A tiny amount of sample was located in the centre of the diamond part, and then a stainless-steel bar was located on the top of the sample surface and pushed using a screw. The collection of each spectrum included an average of 64 scans, and an average of three measurements was employed. The data were collected using OMNIC (Omnic version 8.2, USA) software.

\section{Dissolution Studies}

Dissolution studies were performed at $37^{\circ} \mathrm{C} \pm 0.5^{\circ} \mathrm{C}$ using a Type II dissolution apparatus (Caleva Ltd., Dorset, UK), with $900 \mathrm{~mL}$ of different buffered medium (phosphate buffer $\mathrm{pH} 6.5$ and 7.2 and hydrochloric acid $0.1 \mathrm{~N}$ for $\mathrm{pH} 1.2$ ) using the paddle method with a rotation speed of $100 \pm 2 \mathrm{rpm}$ (23). The experiment was conducted using a pump with an eight-channel head (Automated Lab Systems Ltd., Berkshire, $\mathrm{UK}$ ), linked to a spectrophotometer (he $\lambda$ os $\alpha \mathrm{UV}$-vis, Waltham, MA, Thermo Scientific Inc.). A sample of $20 \mathrm{mg}$ of ZD was placed manually in a hard gelatine capsule (size 0 ), and a sample equivalent to $20 \mathrm{mg} \mathrm{ZD}$ formulation $(200 \mathrm{mg}$ ) was placed manually in a hard gelatine capsule (size 00) and then dropped using a capsule sinker into the dissolution medium. An aliquot $(1 \mathrm{~mL})$ of dissolution medium was transferred to the cuvette automatically at a programmed time interval to determine the absorbance. The percentages of released ZD were calculated by the linear regression equation obtained from the calibration curves prepared using the respective dissolution media.

\section{Solubility Studies}

The solubility of the crystalline ZD was tested by dissolving an excessive amount of drug into each of the solvents $(10 \mathrm{~mL})$ (phosphate buffer $\mathrm{pH} 6.5$ and 7.2 and hydrochloric acid $0.1 \mathrm{~N}$ for $\mathrm{pH} 1.2$ ) in a small beaker. After $24 \mathrm{~h}$ of continuous stirring, the solution was left for $24 \mathrm{~h}$ for equilibration and then filtered through a $0.45 \mu \mathrm{m}$ polypropylene syringe-driven microfilter. Ultraviolet-visible (UV-vis) spectrophotometer (Varian Cary Bio 100, Agilent Technologies, USA) was used to quantify the drug in the solutions.

\section{Mucoadhesion Study}

A modified version of the in vitro mucoadhesion model reported by Needleman and Smales was employed. The duration of mucoadhesion of selected polymeric solid dispersion systems (SDZDPS, SDZDHS) on a mammalian excised intestinal tissue was measured (24). In brief, a small piece of sheep's large intestine tissue (freshly obtained from a local butcher) was attached to an iron mesh fixed on a cylindrical base. This system was then placed into a plastic falcon tube. The tube was filled with different media $(\mathrm{pH} 1.2,6.5,7.2)$ up to the tissue $(24,25)$. The whole setup was transferred into a shaking water bath at $37^{\circ} \mathrm{C}$ for $10 \mathrm{~min}$ to equilibrate. A sample formulation $(10 \mathrm{mg})$ was sprinkled on the tissue. The sample was equilibrated on the tissue at $37^{\circ} \mathrm{C}$ for half an hour. Afterwards, a glass cover slip was placed on top of the formulation and a constant pressure was applied with finger for $10 \mathrm{~s}$. The tube containing the tissue and formulation with the cover slip was mounted horizontally in the shaking water bath that was set at 100 strokes per minute. For the first 30 min, the tube was observed every $120 \mathrm{~s}$ for any possible detachment of the cover slip and then every 20 min for up to $20 \mathrm{~h}$. The average cove slip detachment time was determined for three separate measurements.

\section{Cell Viability Assay}

Caco- 2 cells were seeded in 96 -well plates $(20,000$ cells/ well) and incubated for $24 \mathrm{~h}$. A specific volume $(20 \mu \mathrm{L})$ of 
stock solutions $(10 \mathrm{mM})$ of pure drug, solid dispersions with or without drug was added to $180 \mu \mathrm{L}$ media to obtain a final $\mathrm{ZD}$ concentration of $1000 \mu \mathrm{M}$. Then, a 1-log dilutions were done to obtain the following concentration range $(0.001 \mu \mathrm{M}$, $0.01 \mu \mathrm{M}, 0.1 \mu \mathrm{M}, 1.0 \mu \mathrm{M}, 10 \mu \mathrm{M}$ and $100 \mu \mathrm{M})$. The positive control used in this study was actinomycin D $(100 \mu \mathrm{M})$. The Caco- 2 cell lines were treated for $24 \mathrm{~h}$, after which they were incubated for $3 \mathrm{~h}$ with $40 \mu \mathrm{g} / \mathrm{mL}$ neutral red in the medium. The cells were later washed with D-PBS and the dye was extracted using de-stain solution (1\% acetic acid in $50 \%$ hydroalcoholic acid solution). The absorbance was measured at $540 \mathrm{~nm}$ using a BioTek plate reader (Epoch Microplate Spectrophotometer, Winooski, United States).

\section{RESULTS AND DISCUSSION}

\section{Scanning Electron Microscopy}

SEM was employed to examine the surface morphology of ZD, PVP, HPMC and Eudragit S100 in their pure states, and solid dispersions prepared by the spray drier (Figure 1). While pure ZD SEM image reveals rod-shaped coarse (large) crystals, PVP appeared as irregular spherical particles, HPMC as irregular flake particles and Eud S100 as regular spherical particles.

The SDZDPS dispersion appeared as agglomerates of collapsed spheres, while SDZDHS, SDZDHS-M and SDZDHS-Z consisted of clusters of particles. All ternary solid dispersions had a markedly smaller particle size compared with untreated pure ZD. These favourable dimensions and morphology contribute to the larger surface areas in contact with the dissolution media in vivo and hence are likely to have a significant impact and increase dissolution rate of the drug from these spray-dried formulations (26).

\section{X-ray Diffractometry}

Figure 2 shows the diffractograms of pure ZD, PVP, HPMC, Eudragit S100 and the spray-dried solid dispersions. Several diffraction peaks are clear in the diffractogram of ZD at $15.1^{\circ}, 16.1^{\circ}, 18.6^{\circ}, 19.2^{\circ}, 20.6^{\circ}, 22.5^{\circ}, 24.2^{\circ} 26.2^{\circ}$ and $26.4^{\circ}$. Similar peaks were reported in previous study which were attributed to drug crystallinity (27). PVP, HPMC and Eudragit S100 showed no sharp peaks in their diffractograms which is attributed to their availability in the amorphous form. None of the ZD peaks can be observed in any of the ternary solid dispersions. This observation indicates that ZD was successfully converted into an amorphous or molecular dispersed form (28). The amorphous form is likely to show higher saturation solubility than the crystalline forms due to its higher free energy levels (29). For example, amorphous state formation of nimesulide using PVP solid dispersion resulted in greater enhancement of dissolution rates and solubility of this insoluble drug (30).

\section{Differential Scanning Calorimetry (DSC)}

DSC has been employed to investigate the solid-state changes of $\mathrm{ZD}$ in the formulated solid dispersions. Figure 3 displays the DSC thermograms of ZD, PVP, HPMC, Eudragit S100 and their solid dispersions. ZD shows a sharp endothermic melting peak at $192.01 \pm 0.06^{\circ} \mathrm{C}$, which confirms its crystallinity (31). On the other hand, thermograms for PVP, HPMC and Eudragit S 100 show the lack of melting peak which confirm they are in amorphous forms. Figure 3 shows that typical sharp and strong ZD melting peak was completely missed and replaced with a very shallow and broad peak in all solid dispersions thermograms which suggests the successful drug conversion into its amorphous form. Analysis by the DSC using heat-cool-heat cycle provided the glass transition temperature $(\mathrm{Tg})$ of each of the polymers and dispersions (Table 2). All ternary dispersions have shown a single glass transition $(T g)$ with the lack of an endothermic event. This indicates the presence of ZD in the amorphous state and formation of homogeneous dispersions of ZD within these polymers. These results agree with the XRD data, which indicate that ZD was amorphous in all of the solid dispersion formulations.

\section{Fourier-Transform Infrared Spectroscopy (FT-IR)}

The IR spectrum of ZD (Figure 4) shows a sharp peak at $3397 \mathrm{~cm}^{-1}$ that was assigned to the secondary amine group (the secondary amine stretching range is 3500-3100 $\mathrm{cm}^{-1}$ ) (32). Polyvinylpyrrolidone (PVP) has an amide carbonyl group in its structure, which shows a characteristic sharp peak (Figure 4) at $1664 \mathrm{~cm}^{-1}(33)$. HPMC has residual free $\mathrm{OH}$ groups, which produces a peak at $3455 \mathrm{~cm}^{-1}(33)$. The carbonyl group of Eudragit S100 shows a peak (Figure 4) at $1724 \mathrm{~cm}^{-1}(34)$. In probing interactions between the drug and polymers, the spectra of pure $\mathrm{ZD}$ were used in combination with spectrum of the polymers as references to compare with those of the solid dispersions. The spectra (Figure 4) of the solid dispersion show differences when compared with the pure drug (Figure 4). The ZD solid dispersion secondary amine peak disappeared and a broad peak at the same wavenumber range was observed in all dispersions, which is indicative of the interaction (hydrogen bonds) between the $\mathrm{O}-$ and $\mathrm{NH}$ groups of the drug and polymers. Further, the disappearance of fingerprint region of IR spectra of ZD at 1300 to $600 \mathrm{~cm}^{-1}$ with solid dispersed mixtures could be ascribed to drug-excipient interactions, alteration of drug crystallinity and alteration of main functional groups. These favourable electrostatic interactions are likely to support the formation of amorphous/molecular dispersion and are in agreement with DSC and XRPD data.

\section{Solubility Studies}

In this study, the solubility of the drug alone in different $\mathrm{pH}$ values simulating $\mathrm{pH}$ of GIT was studied: $\mathrm{pH} 1.2$ (gastric $\mathrm{pH}$ ), pH 6.5 (small intestine $\mathrm{pH}$ ) and $\mathrm{pH} 7.2$ (colon $\mathrm{pH}$ ). The results summarised in Table 3 indicate that the solubility of gefitinib is $\mathrm{pH}$ dependent. The drug is relatively highly soluble in the gastric $\mathrm{pH}$, compared to intestinal and colonic $\mathrm{pH}$ values.

Table 3 shows the solubility of $\mathrm{ZD}(\mu \mathrm{g} / \mathrm{mL})$ at $\mathrm{pH}$ values $7.2,6.5$ and 1.2. Solubility data are provided in both linear and logarithmic forms. 

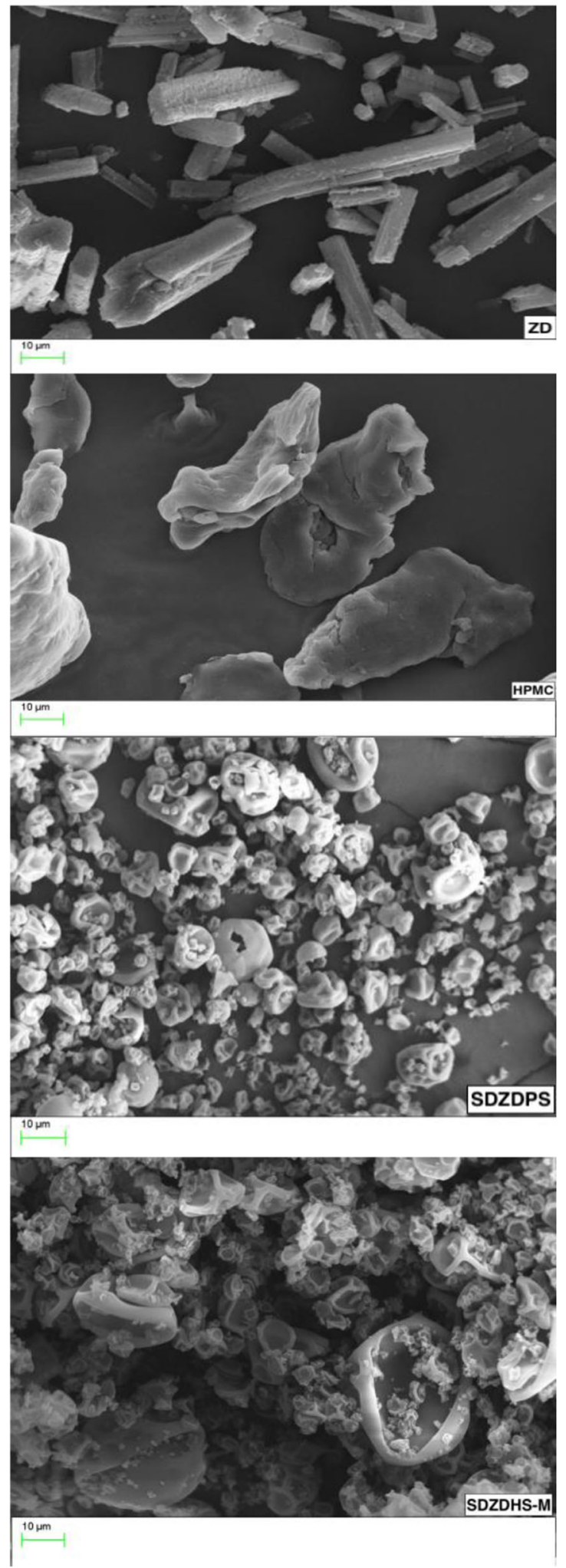
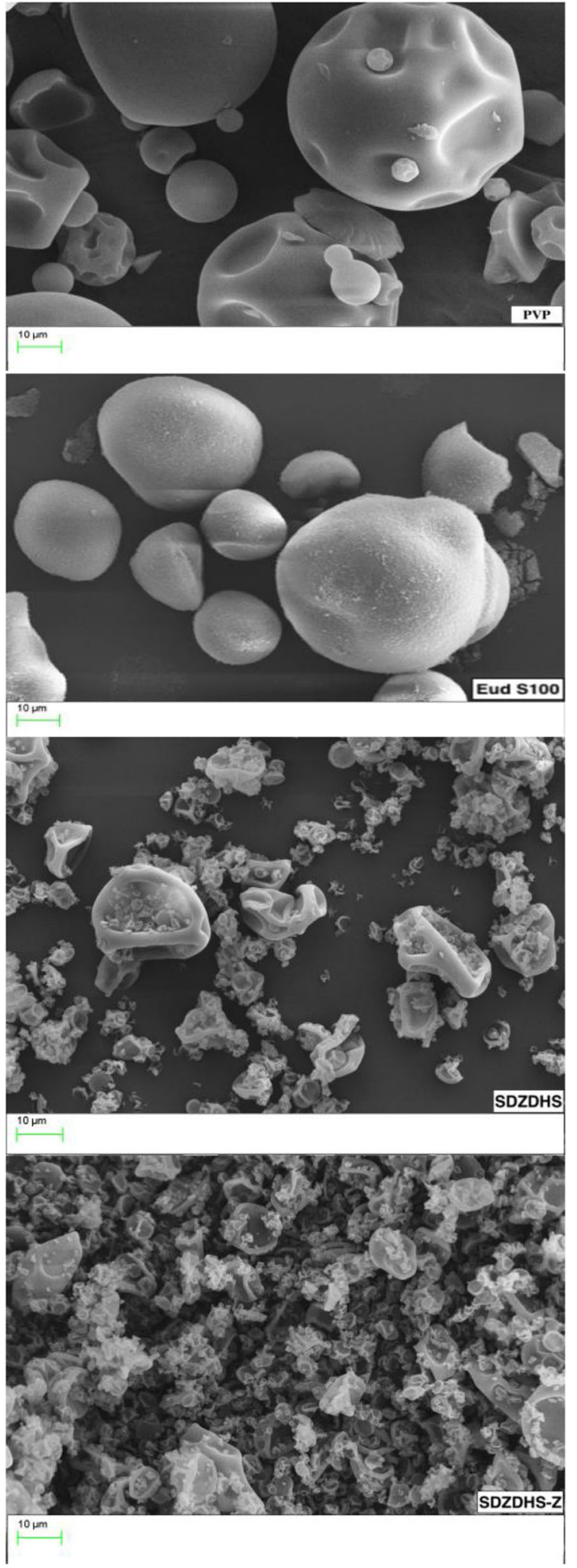

Fig. 1. SEM images displaying the morphology of ZD, PVP, HPMC, Eud S100, SDZDPS, SDZDHS-M and SDZDHS-Z 

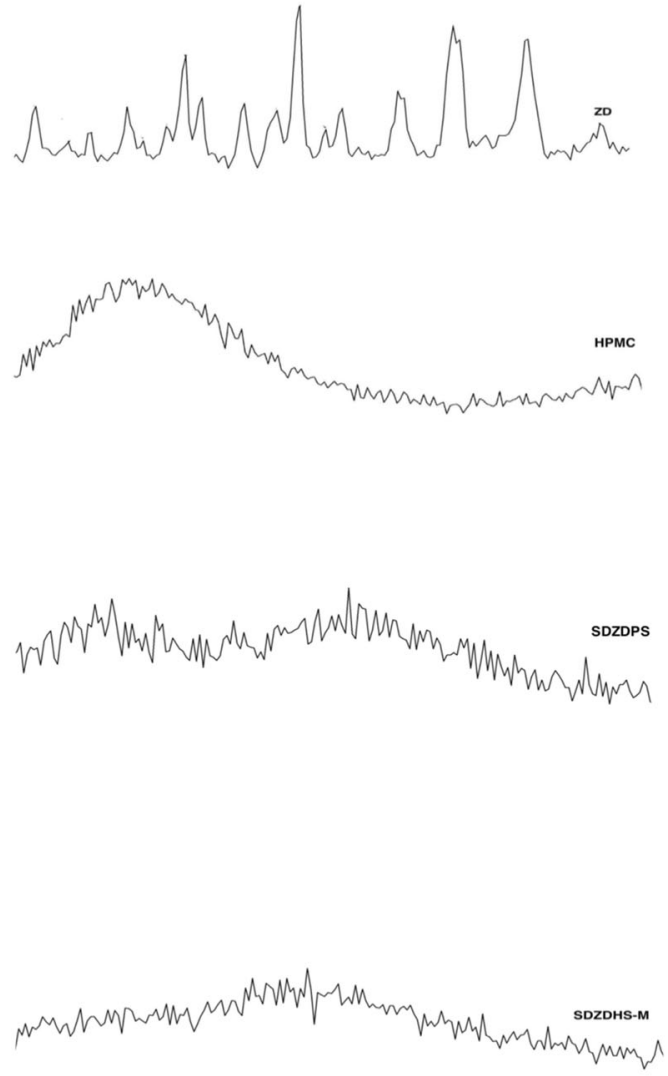

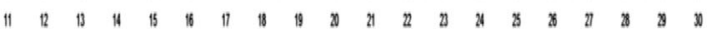

2. Theta- Scale

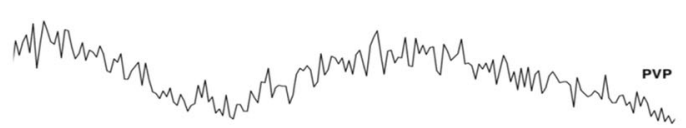

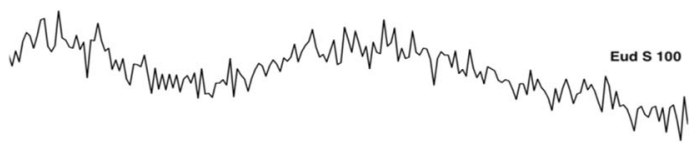

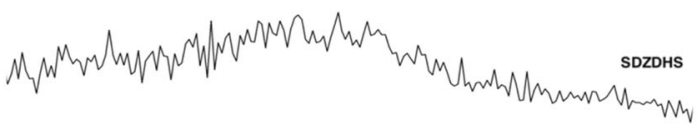

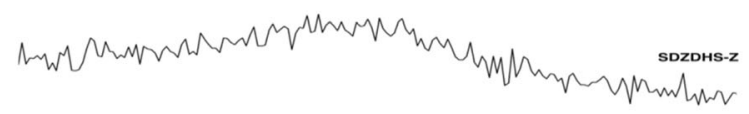

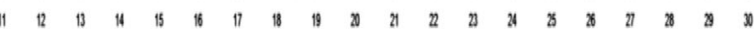

2.Theta - Scale

Fig. 2. X-ray powder diffractograms of ZD, PVP, HPMC, Eudragit S 100 and the solid dispersions

\section{Dissolution Studies}

Figure 5 shows dissolution profiles of pure and solid dispersion formulations at $\mathrm{pH}$ 1.2. ZD used as a reference in dissolution studies is a weak base with two pKa values of 5.4 and 7.2. At low $\mathrm{pH}, \mathrm{ZD}$ is fully ionised and its water solubility is high. Nearly all (94\%) of pure ZD dissolved within half an hour at $\mathrm{pH}$ 1.2. On the other hand, SDZDPS and SDZDHS solid dispersions released only small percentages of the loaded drug, typically $16 \%$ and $15.5 \%$ respectively at $\mathrm{pH}$ 1.2 , over a relatively longer time period of $3 \mathrm{~h}$ (Figure 5). These behaviours could be ascribed to effect of polymeric matrices of PVP, HPMC and Eudragit S 100 on the release of ZD. In order to achieve targeted colon delivery, a further suppression of drug release at $\mathrm{pH} 1.2$ was needed. Therefore, the SDZDHS solid dispersion was optimised by increasing the Eudragit S 100 (hydrophobic polymer) content (see Table 1 for quantitative composition) to further suppress drug release at $\mathrm{pH}$ 1.2. The optimised formulation (SDZDHS-M) showed an enhanced retardation of drug release at $\mathrm{pH} 1.2$ as compared to SDZDHS. Increasing the Eudragit S 100 content (i.e. formulation SDZDHS-Z) would potentially promote better colonic targeting and performance.
Figure 6 shows dissolution profiles of pure and processed $\mathrm{ZD}$ at $\mathrm{pH} 6.5$. Only $38.3 \%$ of pure drug was released in $\mathrm{pH}$ 6.5 after $6 \mathrm{~h}$. Lower dissolution extent and rate were recorded for the pure drug at $\mathrm{pH} 6.8$ compared to that at $\mathrm{pH}$ 1.2. This $\mathrm{pH}$-dependent behaviour is due to lower percentage of ionisation and hence lower solubility and dissolution of this basic drug (ZD) at the higher $\mathrm{pH}$ values, compared to acidic $\mathrm{pH}$ where the drug is almost completely ionised. Further retardation in dissolution rates was recorded for SDZDPS, SDZDHS, SDZDHS-M and SDZDHS-Z solid dispersion. Only $2.5 \%, 4.1 \%, 0.9 \%$ and $0.2 \%$ of loaded drug were released at pH 6.5 (after $6 \mathrm{~h}$ ), respectively. The presence of Eudragit S100 plays a crucial role in potential colon targeting by preventing the drug release at segments of the GIT other than the colon.

Figure 7 shows the dissolution profiles of pure and processed $\mathrm{ZD}$ at $\mathrm{pH}$ 7.2. Only $28.7 \%$ of pure drug was released in less than $12 \mathrm{~h}$ in $\mathrm{pH}$ 7.2. SDZDPS, SDZDHS and SDZDHS-M solid dispersion released $96.7 \%, 76.7 \%$ and $89 \%$ of loaded drug at pH 7.2 (after 12 h), respectively. Increasing the ratio of Eudragit S (i.e. formulation SDZDHS$\mathrm{Z})$ displayed the best colonic controlled-release performance as shown in (Figures 5 and 6). However, the increase in 

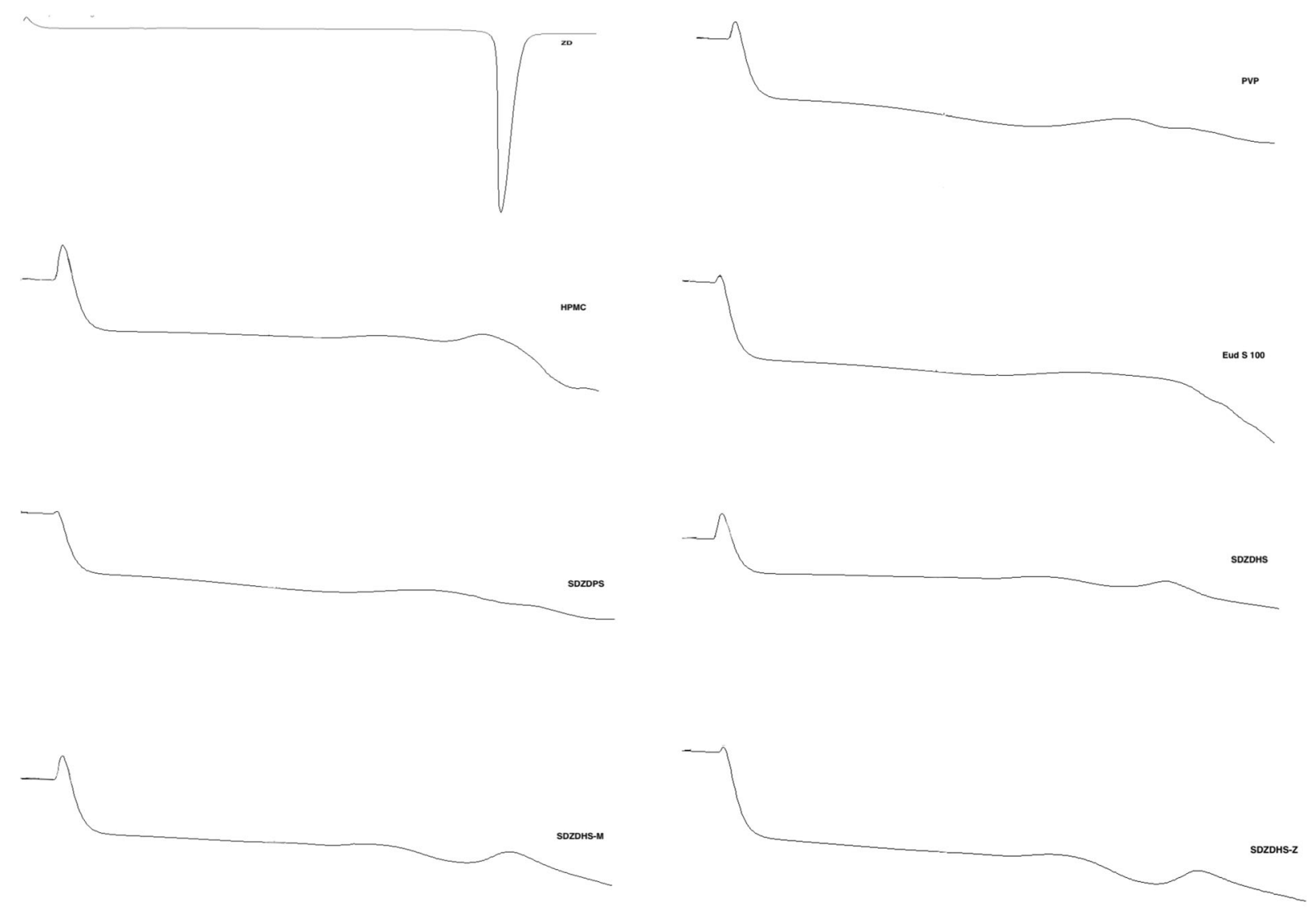

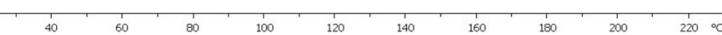

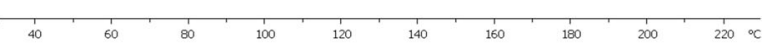

Fig 3. DSC thermograms of ZD, PVP, HPMC, Eud S 100 and their solid dispersion

Eudragit S 100 content resulted in a slower release rate at $\mathrm{pH}$ 7.2 as shown in (Figure 7); therefore, the run time was extended for this formulation to $15 \mathrm{~h}$ to allow a maximum drug release to take place (data not shown). Increasing Eudragit S100 concentration is likely to produce a denser polymeric matrix in order to increase the production at low $\mathrm{pH}$, and hence, more time is required for polymer to dissolve and release drug molecules.

Almost $100 \%$ of the drug was released from the SDZDHS-Z solid dispersion within $15 \mathrm{~h}$ at $\mathrm{pH} 7.2$ (data not shown). HPMC 603 and PVP were used to enhance the drug

Table 2. $T \boldsymbol{g}$ Values of PVP, HPMC, Eud S 100 and Solid Dispersions

\begin{tabular}{ll}
\hline Dispersion constituent & $\operatorname{Tg}\left({ }^{\circ} \mathrm{C}\right)$ \\
\hline PVP & $160.21 \pm 0.57$ \\
HPMC & $125.91 \pm 0.31$ \\
Eudragit S 100 & $160.61 \pm 0.54$ \\
SDZDPS & $152.37 \pm 0.25$ \\
SDZDHS & $122.49 \pm 1.34$ \\
SDZDHS-M & $122.95 \pm 0.93$ \\
SDZDHS-Z & $122.17 \pm 0.43$ \\
\hline
\end{tabular}

dissolution in the first place, while the role of Eud S 100 was to prevent the drug release in the upper GIT. The solubility of the drug at basic $\mathrm{pH}$ seems to be very low and this partly contributes to prolonged dissolution rates. Similar results were reported with HPMC colon targeted paracetamol capsules with two enteric polymers Eudragit L 30 D-55 and Eudragit FS 30 D. The dissolution studies showed gastric resistant release for $2 \mathrm{~h}$ at $\mathrm{pH} 1.2$ and capsules coated with Eudragit FS $30 \mathrm{D}$ were resistant for a more $1 \mathrm{~h}$ at $\mathrm{pH} 6.8$ (35).

\section{Mucoadhesion Study}

PVP is one of the most commonly used polymers to make solid dispersions, hence chosen to enhance the dissolution of the poorly water-soluble drug; ZD (36). However, there is no evidence in the literature to suggest that PVP is mucoadhesive. Mucoadhesion happens when a substrate is attracted (via various forces) to a mucus layer that coats the epithelium of a tissue. Mucoadhesiveness is a useful characteristic as it can potentially prolong retention time of a formulation at a target site and maximise the contact time with the bio-absorption site to increase drug permeability through biological membranes(21). In this study, the watersoluble carrier (HPMC) was employed to enhance the mucoadhesion properties of the optimised formulation. This 


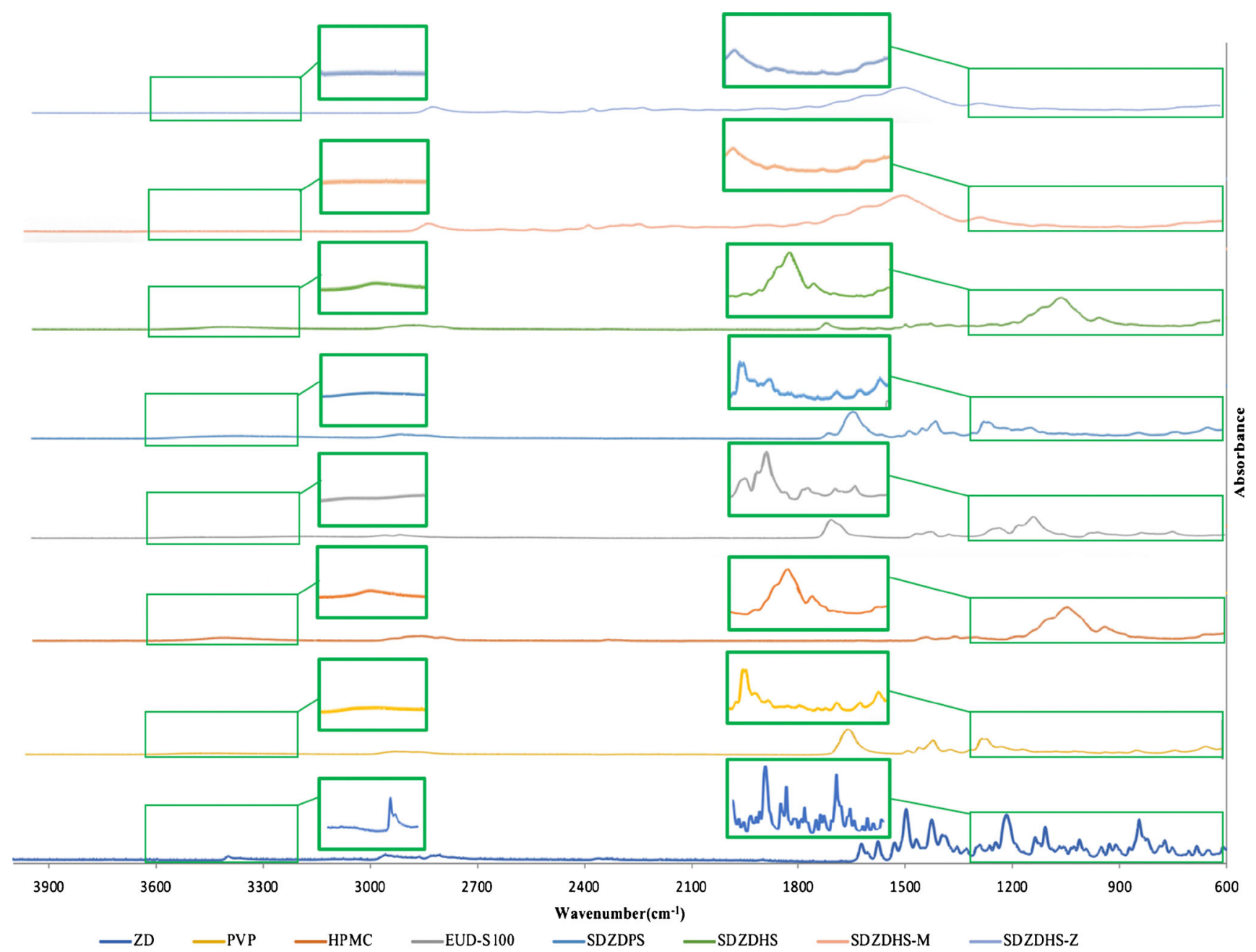

Fig. 4. IR spectra of ZD, PVP, HPMC and EUD-S100, and their solid dispersion over the spectral region between 600 and $4000 \mathrm{~cm}^{-1}$

is likely due to availability of hydroxyl groups $(\mathrm{OH})$ groups to form $\mathrm{H}$-bonding and electrostatic attractions with mucin. The rotating cylinder method was used to estimate the time of adhesion to the tissue of formulated PVP, and HPMC solid dispersions in the presence of Eudragit S100 (24). The evaluation of adhesion of the formulations depends on the time that the glass slide remains in contact with the tissue. The longer the adhesion time, the stronger the mucoadhesion forces.

Table 4 provides a summary of mucoadhesion time of all tested formulations at the $\mathrm{pH}$ values of interest. While there was no significant difference in the retention times $(P$-value $=$ 0.09 and 0.37 respectively) between SDZDPS and SDZDHS formulations at $\mathrm{pH} 1.2$ and $\mathrm{pH} 6.5$ (relatively poor adhesion

Table 3. Solubility of ZD at Different pHs. Mean \pm SD, $\boldsymbol{n}=3$

\begin{tabular}{lll}
\hline $\mathrm{pH}$ & Solubility $(\mu \mathrm{g} / \mathrm{mL})$ & Log solubility \\
\hline 1.2 & $1000 \pm 1.6$ & $3.0 \pm 0.2$ \\
6.5 & $11 \pm 1.25$ & $1.04 \pm 0.1$ \\
7.2 & $10 \pm 1.12$ & $1.0 \pm 0.05$ \\
\hline
\end{tabular}

at gastric and upper GIT pH), a significant increase of retention times $(P$-value $=0.00016)$ was observed at the $\mathrm{pH}$ 7.2 (Table 4). Indeed, Eudragit S100 seems to have a protective effect at lower $\mathrm{pH}$ where it prevents the system from dissolving, consequently limiting mucoadhesion. Further, at higher $\mathrm{pH}>7$, the carboxylate groups of mucin are fully ionised and can better interact with HPMC. In addition, as the $\mathrm{pH}$ increases above the dissolution threshold for Eudragit S (> pH 7), SDZDHS (containing Eudragit and HPMC) showed a higher duration of adhesion (1188 min) comparing with PVP containing SDZDPS (269 min). This synergistic effect can be possibly attributed to the ability of HPMC to swell on contact with aqueous media, causing increases in the unfolding of the polymeric network and free chain mobility resulting in an increase in polymer-mucin interactions by entanglement and/or by hydrogen bonding (21). Such pH-dependent mucoadhesion profile is expected to specifically prolong retention time of $\mathrm{ZD}$ at the target site. This is important to maximise the retention of $\mathrm{ZD}$ formulation at the ascending colon where fluid is relatively more abundant allowing an enhanced dissolution and absorption. Therefore, HPMC was used instead of PVP in solid dispersion formulations with ZD and Eudragit S 100 to carry out further optimisation. The longer the adhesion time, the better 


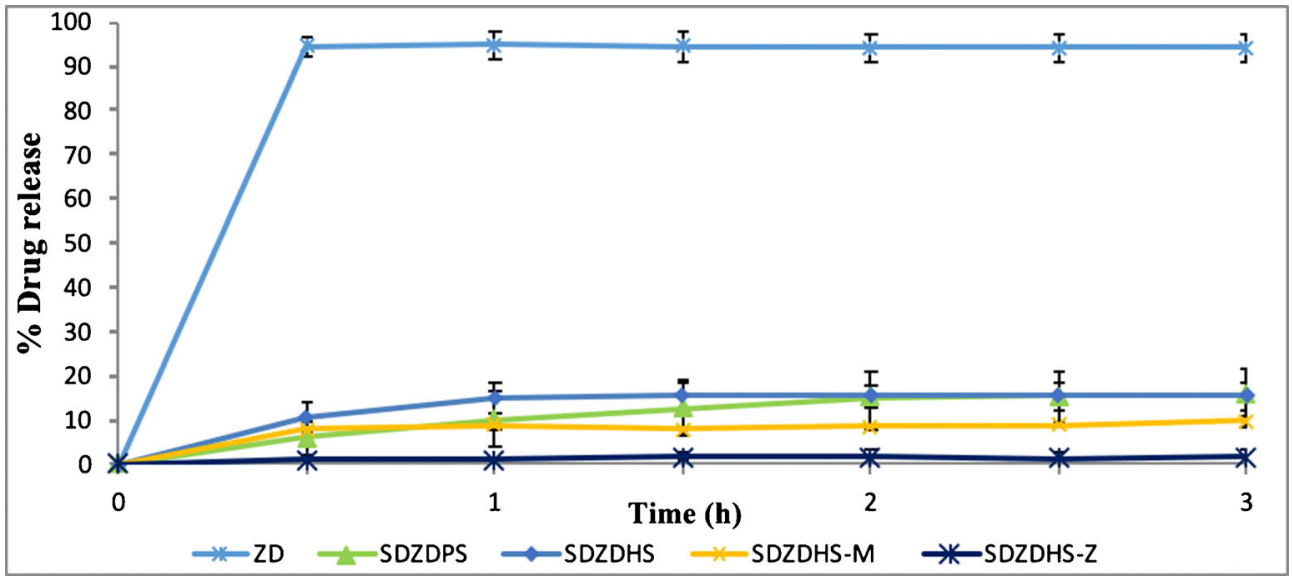

Fig 5. The dissolution profile for Crystalline Gefitinib and spray-dried formulations into $\mathrm{pH} 1.2$; mean \pm SD, three independent batches were analysed, each 6 times $(\boldsymbol{n}=18)$

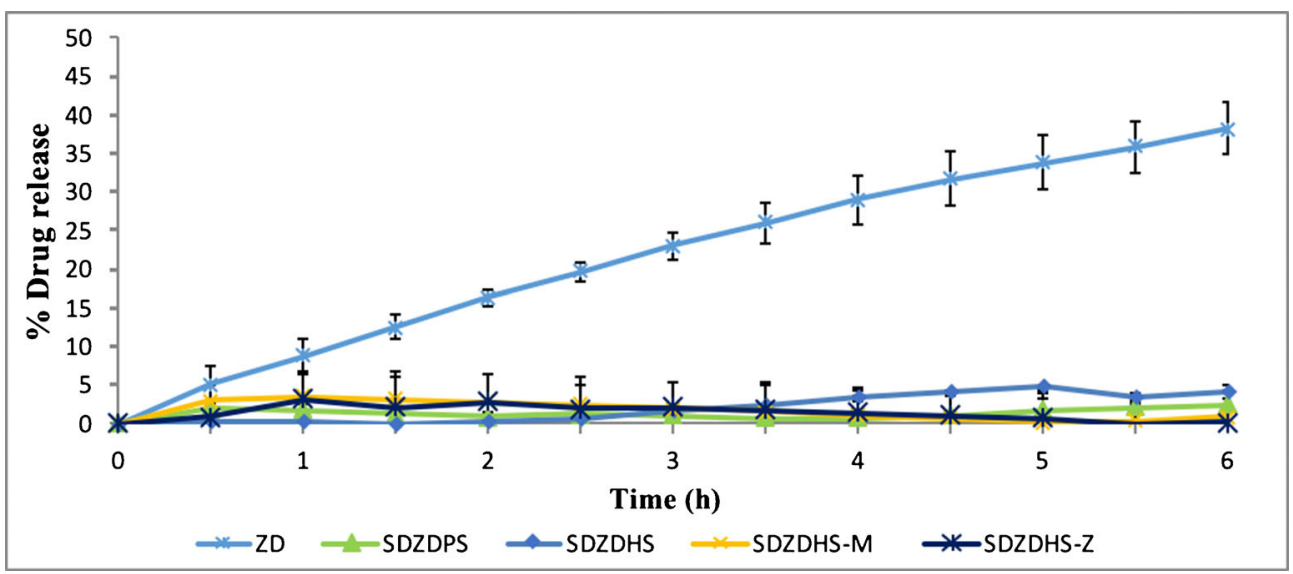

Fig 6. The dissolution profile for Crystalline Gefitinib and spray-dried formulations into $\mathrm{pH} 6.5$; mean \pm $\mathrm{SD}$, three independent batches were analysed, each 6 times $(\boldsymbol{n}=18)$

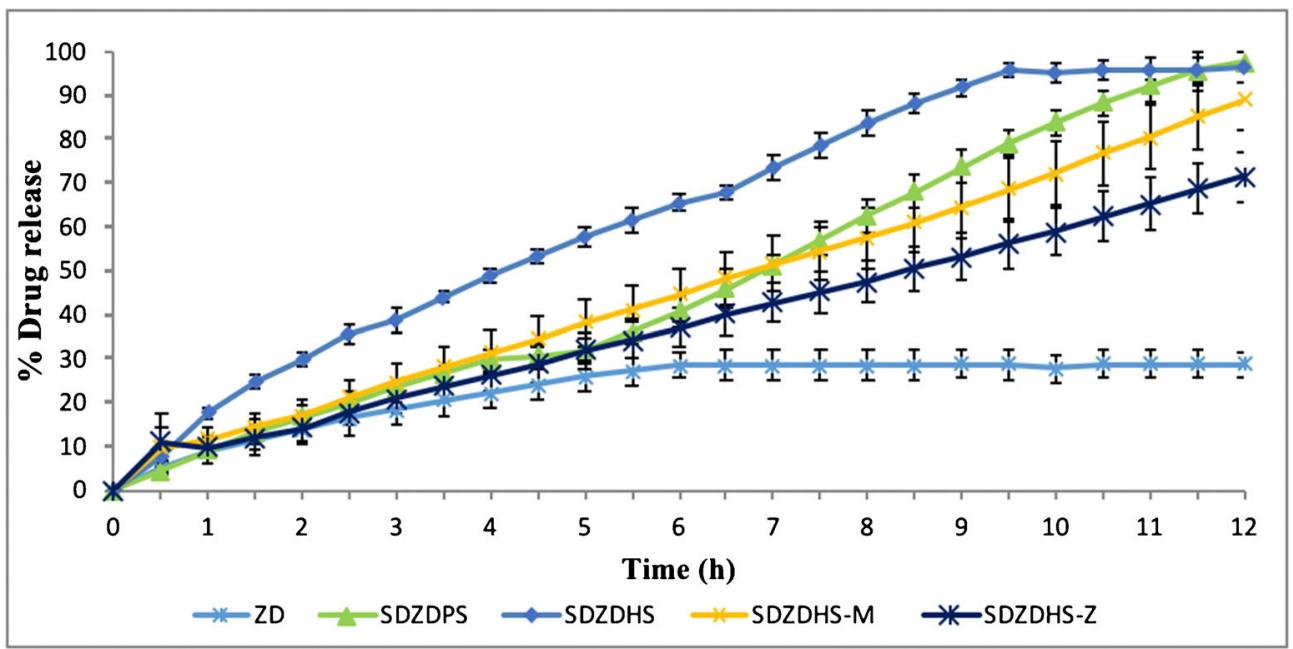

Fig 7. The dissolution profile for Crystalline Gefitinib and spray-dried formulations into $\mathrm{pH} 7.2$; mean \pm $\mathrm{SD}$, three independent batches were analysed, each 6 times $(\boldsymbol{n}=18)$ 
Table 4. Duration of Mucoadhesion of Solid Dispersion Formulations at Different $\mathrm{pHs}$

\begin{tabular}{lcccc}
\hline Formulation & & & \multicolumn{2}{l}{ Adhesion time (min) } \\
\cline { 5 - 5 } & $\mathrm{pH} \mathrm{1.2}$ & & $\mathrm{pH} \mathrm{6.5}$ & $\mathrm{pH} \mathrm{7.2}$ \\
\hline SDZDPS* & $7 \pm 1.0$ & & $5 \pm 0.6$ & $269 \pm 41.8$ \\
SDZDHS* & $9 \pm 1.5$ & & $6 \pm 1.0$ & $1188 \pm 153.7$ \\
\hline
\end{tabular}

*P, PVP; $H$, HPMC; $S$, Eudragit S 100

retention where more time is allowed for drug uptake by target tissues. For example, xanthan gums, chitosan and polyethylene oxide polymers recorded adhesion times of 153.5, 43 and 89 min respectively (37). However, the adhesion time recorded for SDZDHS was approx. $20 \mathrm{~h}$. This is a relatively lengthy time for an ex vivo study that might lead to some changes in properties of the excised tissue, a matter that needs to be taken into consideration when interpreting these results. Nevertheless, these findings indicate that HPMC has superior mucoadhesive properties compared to PVP. PVP is one of the most commonly used polymers with solid dispersions, hence chosen to enhance the dissolution of the poorly water-soluble drug; ZD (36). Interestingly, there is no evidence in the literature to suggest that PVP is mucoadhesive.

\section{Cell Viability Assay}

Neutral red uptake is one of the most commonly used viability assays that provide a quantitative estimation of the number of viable cells. This test is reliable and provides fast background absorbance when measured in the absence of cells. Furthermore, it has been reported to be more sensitive and cheaper than other tetrazolium salts-based cytotoxicity assays (38). Viable cells have the ability to incorporate and bind the neutral red supravital dye in lysosomes, which is later extracted (38). This test has been successfully employed to evaluate the cytotoxicity of polyelectrolyte nanocomplex of chitosan and hyalurnoic acid for colon delivery of insulin (39). In this study, caco- 2 cell lines were dosed, and the treatment range was picked up in accordance with the $\mathrm{IC}_{50}$ value of $0.033 \mu \mathrm{M}$ for pure $\mathrm{ZD}$ under the conditions and exposure times as previously described (40). Serial dilutions of drugfree polymeric dispersions (SDHS), drug (ZD) and drugloaded spray-dried dispersions (SDZHS-Z) of different concentrations $(0.001 \mu \mathrm{M}, 0.01 \mu \mathrm{M}, 0.1 \mu \mathrm{M}, 1.0 \mu \mathrm{M}, 10 \mu \mathrm{M}$ and $100 \mu \mathrm{M}$ ) were tested for cell viability against positive and negative control (Figure 8). Cell viability (\%) recorded for SDHS (drug free polymeric dispersions) at concentrations from 0.001 to $100 \mu \mathrm{M}$ was $100 \%$ indicating high tolerability and no cytotoxicity to the excipients used. On the contrary, concentration-dependent cytotoxicity was reported to drug alone and drug formulated as spray-dried dispersion. These results indicate that the used excipients/polymers used had no cytotoxic effects comparable to the negative control and hence can be considered as non-toxic (41). However, it is worthwhile noting that the HPMC solid dispersion loaded with drug (SDZDHS-Z) are likely to remain in contact with the target tissue (colon) for prolonged time period (as demonstrated by the mucoadhesion results (previous section)), which along with the improved dissolution and extended release of $\mathrm{ZD}$ could potentially translate to improved efficacy in vivo. Hence, the importance of further proof-of-concept studies to be conducted in vivo using an appropriate animal model.

Figure 8 shows the percentage of cell variability (Caco-2) with increasing concentrations of pure ZD, HPMC solid dispersion loaded with drug (SDZDHS-Z) and blank formulation (SDHS). It is apparent that treatment with pure drug and formulated drug as solid dispersion causes Caco-2 cell growth inhibition. The response of Caco- 2 cells to treatment appears to be dose-dependent with comparable growth

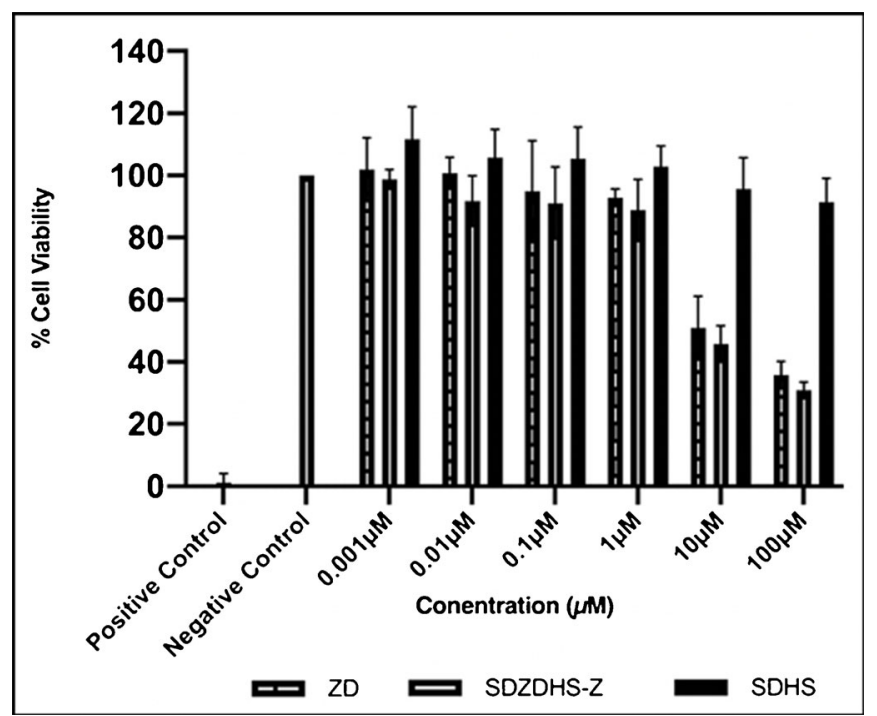

Fig. 8. The effect of ZD, SDZDHS-Z and SDHS on the growth of Caco- 2 cell after $24 \mathrm{~h}$ using the neutral red; $\boldsymbol{n}=3$ 
inhibition results for both pure (ZD) and processed drug (SDZDHS-Z) at all concentrations $(P>0.05)$. This indicates that the used excipients and the formed solid dispersions do not interfere with cytotoxic effects of the drug. Further, it is worthwhile mentioning that while the formulation tested (SDZDHS-Z) was not superior to the pure drug (ZD) in inhibiting cell growth, one needs to remember that cell culture studies are conducted in an environment that would not allow the desirable mucoadhesive properties of (SDZDHS-Z) to affect the formulation's performance. Hence, the need to further investigate these formulations in an appropriate in vivo(animal) model.

\section{CONCLUSION}

In this study, we reported (for the first time) on polymeric formulations of ZD that were prepared by a simple and scalable spray drying method. Formulations based on HPMC and Eudragit S 100 showed an enhancement in dissolution and mucoadhesion of (ZD) which could potentially result in improved colonic delivery of ZD. The spray drying method was successfully employed to preparer amorphous micronised spherical particles of $\mathrm{ZD}$ in polymeric carriers comprising PVP or HPMC with Eudragit S 100. The $\mathrm{pH}$-dependent dissolution profiles and mucoadhesion characteristics were demonstrated by all formulations with the HPMC-based solid dispersion being the most promising. The neutral red assay results conducted on a $\mathrm{Caco} 2$ cell line showed a dose-dependent response which was not affected by the polymers or spray drying process used. Yet, the HPMCbased drug-free formulation had no toxic effects on cells. This can warrant further investigation of the prepared formulations in an appropriate animal model where the effect of mucoadhesion on efficacy could be established.

\section{AUTHOR CONTRIBUTION}

Wesam W. Mustafa: The acquisition, analysis, interpretation of data for the work and drafting the work. John Fletcher: Substantial contributions to the conception, design of the work, revising the work critically for important intellectual content. Mohamed Khoder: Revising the work critically for important intellectual content. Raid Alany: Substantial contributions to the conception, design of the work, revising the work critically for important intellectual content, and final approval of the version to be published.

\section{DECLARATIONS}

Conflict of Interest The authors declare no competing interests.

Open Access This article is licensed under a Creative Commons Attribution 4.0 International License, which permits use, sharing, adaptation, distribution and reproduction in any medium or format, as long as you give appropriate credit to the original author(s) and the source, provide a link to the Creative Commons licence, and indicate if changes were made. The images or other third party material in this article are included in the article's Creative Commons licence, unless indicated otherwise in a credit line to the material. If material is not included in the article's Creative Commons licence and your intended use is not permitted by statutory regulation or exceeds the permitted use, you will need to obtain permission directly from the copyright holder. To view a copy of this licence, visit http://creativecommons.org/licenses/by/4.0/.

\section{REFERENCES}

1. Lynch TJ, Bell DW, Sordella R, Gurubhagavatula S, Okimoto RA, Brannigan BW, Harris PL, Haserlat SM, Supko JG, Haluska FG, Louis DN, Christiani DC, Settleman J, Haber DA. Activating mutations in the epidermal growth factor receptor underlying responsiveness of non-small-cell lung cancer to gefitinib. NEJM. 2004;350(21):2129-39.

2. Takimoto $\mathrm{CH}$, Calvo E. Principles of oncologic pharmacotherapy. In: Pazdur R, Wagman LD, Camphausen KA, Hoskins WJ, editors. Cancer Management: A Multidisciplinary Approach. UBM Medica: London, UK; 2008.

3. Mayer A, Takimoto M, Fritz E, Schellander G, Kofler K, Ludwig $\mathrm{H}$. The prognostic significance of proliferating cell nuclear antigen, epidermal growth factor receptor, and $\mathrm{mdr}$ gene expression in colorectal cancer. Cancer. 1993;71:2454-60.

4. Rubinstein A. Microbially controlled drug delivery to the colon. Biopharm Drug Dispos. 1990;11(6):465-75.

5. Kinget R, Kalala W, Vervoort L, Van den Mooter G. Colonic drug targeting. J Drug Target. 1998;6(2):129-49.

6. Singh N, Khanna R. Colon targeted drug delivery systems-a potential approach. The Pharma Innovation. 2012;1(2):79-87.

7. Chourasia M, Jain S. Design and development of multiparticulate system for targeted drug delivery to colon. Drug Delivery. 2004;11(3):201-7.

8. Wathoni N, Nguyen AN, Rusdin A, Umar AK, Mohammed AFA, Motoyama K, et al. Enteric-coated strategies in colorectal cancer nanoparticle drug delivery system. Drug Des Devel Ther. 2020;14:4387.

9. Lee SH, Bajracharya R, Min JY, Han J-W, Park BJ, Han H-K. Strategic approaches for colon targeted drug delivery: an overview of recent advancements. Pharmaceutics. 2020;12(1):68.

10. Alange VV, Birajdar RP, Kulkarni RV. Novel spray dried pHsensitive polyacrylamide-grafted-carboxymethylcellulose sodium copolymer microspheres for colon targeted delivery of an anti-cancer drug. J Biomater Sci Polym Ed. 2017;28(2):13961.

11. European Medicines Agency. CHMP assessment report: Iressa (gefitinib). London: The Agency. 2009;Jul.EMEA/CHMP/ 563746/2008.

12. Bergman E, Forsell P, Persson EM, Knutson L, Dickinson P, Smith R, Swaisland H, Farmer MR, Cantarini MV, Lennernäs H. Pharmacokinetics of gefitinib in humans: the influence of gastrointestinal factors. Int J Pharm. 2007;341(1):134-42.

13. Amidon GL, Lennernäs H, Shah VP, Crison JR. A theoretical basis for a biopharmaceutic drug classification: the correlation of in vitro drug product dissolution and in vivo bioavailability. Pharm Res. 1995;12(3):413-20.

14. Alanazi A, Alshehri S, Altamimi M, Shakeel F. Solubility determination and three dimensional Hansen solubility parameters of gefitinib in different organic solvents: experimental and computational approaches. J Mol Liq. 2020;299:112211.

15. Talsma H, Steenbergen MJV, Borchert JCH, Crommelin DJA. A novel technique for the one-step preparation of liposomes and non-ionic surfactant vesicles without the use of organic solvents. Liposome formation in a continuos gas stream: the bubble method. J Pharm Sci. 1994;83:276-80.

16. Ashford M, Fell JT, Attwood D, Woodhead PJ. An in vitro investigation into the suitability of $\mathrm{pH}$-dependent polymers for colonic targeting. Int J Pharm. 1993;91(2):241-5. 
17. Serajuddin A. Solid dispersion of poorly water-soluble drugs: early promises, subsequent problems, and recent breakthroughs. J Pharm Sci. 1999;88(10):1058-66.

18. Ibekwe VC, Fadda HM, Parsons GE, Basit AW. A comparative in vitro assessment of the drug release performance of $\mathrm{pH}$ responsive polymers for ileo-colonic delivery. Int $\mathrm{J}$ Pharm. 2006;308(1):52-60.

19. Motallae S, Taheri A, Homayouni A. Preparation and characterization of solid dispersions of celecoxib obtained by spraydrying ethanolic suspensions containing PVP-K30 or isomalt. J Drug Deliv Sci Technol. 2018;46:188-96.

20. Smeets A, Koekoekx R, Clasen C, Van den Mooter G. Amorphous solid dispersions of darunavir: comparison between spray drying and electrospraying. Eur J Pharm Biopharm. 2018;130:96-107.

21. Gu JM, Robinson JR, Leung SH. Binding of acrylic polymers to mucin/epithelial surfaces: structure-property relationships. Crit Rev Ther Drug Carrier Syst. 1988;5(1):21-67.

22. Jester J, Barry LP, Petroll W. Inhibition of corneal fibrosis by topical application of blocking antibodies to TGF-beta in the rabbit. Cornea. 1997;16:177-87.

23. Taylor KM, Aulton ME, editors. Aulton's Pharmaceutics EBook: The design and manufacture of medicines. Elsevier Health Sciences; 2017.

24. Needleman IG, Smales FC. In vitro assessment of bioadhesion for periodontal and buccal drug delivery. Biomaterials. 1995;16(8):617-24.

25. Kumar A, Naik PK, Pradhan D, Ghosh G, Rath G. Mucoadhesive formulations: innovations, merits, drawbacks, and future outlook. Pharm Dev Technol. 2020;25:1-18.

26. Esposito E, Roncarati R, Cortesi R, Cervellati F, Nastruzzi C. Production of Eudragit microparticles by spray-drying technique: influence of experimental parameters on morphological and dimensional characteristics. Pharm Dev Technol. 2000;5(2):267-78.

27. Chen W, di Carlo C, Devery D, McGrath DJ, McHugh PE, Kleinsteinberg K, et al. Fabrication and characterization of gefitinib-releasing polyurethane foam as a coating for drugeluting stent in the treatment of bronchotracheal cancer. Int J Pharm. 2018;548(2):803-11.

28. Phillip Lee Y-H, Sathigari S, Jean Lin Y-J, Ravis WR, Chadha G, Parsons DL, Rangari VK, Wright N, Babu RJ. Gefitinibcyclodextrin inclusion complexes: physico-chemical characterization and dissolution studies. Drug Dev Ind Pharm. 2009;35(9):1113-20.

29. Alonzo DE, Zhang GG, Zhou D, Gao Y, Taylor LS. Understanding the behavior of amorphous pharmaceutical systems during dissolution. Pharm Res. 2010;27(4):608-18.

30. Abdelkader H, Abdallah OY, Salem HS. Comparison of the effect of tromethamine and polyvinylpyrrolidone on dissolution properties and analgesic effect of nimesulide. AAPS PharmSciTech. 2007;8(3):E110-E7.

31. Gidwani B, Vyas A, Kaur CD. Investigation of inclusion behaviour of gefitinib with epichlorohydrin- $\beta$-cyclodextrin polymer: preparation of binary complex, stoichiometric determination and characterization. J Pharm Biomed Anal. 2018;160:31-7.

32. Shi Y, Su C, Cui W, Li H, Liu L, Feng B, Liu M, Su R, Zhao L. Gefitinib loaded folate decorated bovine serum albumin conjugated carboxymethyl-beta-cyclodextrin nanoparticles enhance drug delivery and attenuate autophagy in folate receptorpositive cancer cells. J Nanobiotechnology. 2014;12(1):43.

33. Somashekarappa H, Prakash Y, Hemalatha K, Demappa T, Somashekar R. Preparation and characterization of HPMC/PVP blend films plasticized with sorbitol. Indian J Mater Sci. 2013;2013:1-7.

34. Mehta R, Chawla A, Sharma P, Pawar P. Formulation and in vitro evaluation of Eudragit S-100 coated naproxen matrix tablets for colon-targeted drug delivery system. J Adv Pharm Technol Res. 2013;4(1):31-41.

35. Cole ET, Scott RA, Connor AL, Wilding IR, Petereit H-U, Schminke C, Beckert T, Cadé D. Enteric coated HPMC capsules designed to achieve intestinal targeting. Int $\mathrm{J}$ Pharm. 2002;231(1):83-95.

36. Sharma A, Jain C. Preparation and characterization of solid dispersions of carvedilol with PVP K30. Res Pharm Sci. 2010;5(1):49-56.

37. Needleman IG, Smales FC, Martin GP. An investigation of bioadhesion for periodontal and oral mucosal drug delivery. J Clin Periodontol. 1997;24(6):394-400.

38. Repetto G, del Peso A, Zurita JL. Neutral red uptake assay for the estimation of cell viability/cytotoxicity. Nat Protoc. 2008;3(7):1125-31.

39. Sladek S, McCartney F, Eskander M, Dunne DJ, SantosMartinez MJ, Benetti F, Tajber L, Brayden DJ. An entericcoated polyelectrolyte nanocomplex delivers insulin in rat intestinal instillations when combined with a permeation enhancer. Pharmaceutics. 2020;12(3):259.

40. Wakeling AE, Guy SP, Woodburn JR, Ashton SE, Curry BJ, Barker AJ, Gibson KH. ZD1839 (Iressa): an orally active inhibitor of epidermal growth factor signaling with potential for cancer therapy. Cancer Res. 2002;62(20):5749-54.

41. Franco P, De Marco I. The Use of Poly (N-vinyl pyrrolidone) in the delivery of drugs: a review. Polymers. 2020;12(5):1114.

Publisher's Note Springer Nature remains neutral with regard to jurisdictional claims in published maps and institutional affiliations. 